OPEN ACCESS

Edited by:

Giacinto Bagetta,

University of Calabria, Italy

Reviewed by:

Robert I. Barkin

Rush University Medical Center,

United States

Rohit Dhall,

University of Arkansas for Medical

Sciences, United States Ismaeel Yunusa

MCPHS University, United States

${ }^{*}$ Correspondence:

Dorota Religa

dorota.religa@ki.se

Specialty section: This article was submitted to

Neuropharmacology,

a section of the journal

Frontiers in Pharmacology

Received: 28 June 2019

Accepted: 17 July 2020

Published: 31 July 2020

Citation:

Magierski R, Sobow T, Schwertner E and Religa D (2020) Pharmacotherapy

of Behavioral and Psychological

Symptoms of Dementia: State of the

Art and Future Progress.

Front. Pharmacol. 11:1168.

doi: 10.3389/fphar.2020.01168

\section{Pharmacotherapy of Behavioral and Psychological Symptoms of Dementia: State of the Art and Future Progress}

\author{
Radoslaw Magierski ${ }^{1}$, Tomasz Sobow ${ }^{2}$, Emilia Schwertner ${ }^{3}$ and Dorota Religa ${ }^{3,4 *}$ \\ 1 Department of Old Age Psychiatry and Psychotic Disorders, Medical University of Lodz, Lodz, Poland, 2 Dialog Therapy \\ Centre, Warsaw \& Institute of Psychology, University of Lodz, Lodz, Poland, ${ }^{3}$ Center for Alzheimer Research, Division of \\ Clinical Geriatrics, Department of Neurobiology, Care Sciences and Society, Karolinska Institutet, Huddinge, Sweden, \\ ${ }^{4}$ Tema Aging, Karolinska University Hospital, Stockholm, Sweden
}

The core symptoms of different dementia subtypes are the behavioral and psychological symptoms of dementia (BPSD) and its neuropsychiatric symptoms (NPS). BPSD symptoms may occur at any stage in the case of dementia due to Alzheimer's disease (AD), whereas they tend to occur early on in the case of its behavioral variant frontotemporal dementia or dementia with Lewy bodies and are essential for diagnosis. BPSD treatment consists of non-pharmacological as well as pharmacological interventions, with non-pharmacological interactions being suggested as first-line treatment. Agitation, psychotic features, apathy, depression, and anxiety may not respond to acetylcholinesterase inhibitors or memantine in $A D$ cases; therefore, antipsychotics, antidepressants, sedative drugs or anxiolytics, and antiepileptic drugs are typically prescribed. However, such management of BPSD can be complicated by hypersensitivity to antipsychotic drugs, as observed in DLB, and a lack of effective procognitive treatment in the case of frontotemporal dementia. The present paper reviews current knowledge of the management of BPSD and its limitations and discusses ongoing clinical trials and future therapeutic options.

Keywords: behavioral and psychological symptoms of dementia, neuropsychiatric symptoms, antipsychotics, antidepressants, non-pharmacological interventions, clinical trial

\section{INTRODUCTION}

The commonly-observed core symptoms of dementia are classified as behavioral and psychological symptoms of dementia (BPSD) or as neuropsychiatric symptoms (NPS) (Zhao et al., 2016). NPS are mainly associated with Alzheimer's dementia (AD), but they can occur in various types of dementia, as well as in mild cognitive impairment (MCI) (Siafarikas et al., 2018). NPS have been recognized as a risk factor of dementia among individuals with MCI, especially when co-occuring with affective and psychotic symptoms (Liew, 2019). Moreover, cases characterized by behavioral changes and psychiatric symptoms, but without cognitive impairment in later life, have been described as mild behavioral impairment (Taragano et al., 2009); this has been recognized as an at-risk state for 
cognitive decline and dementia, biomarker of cognitive decline, or even a potential manifestation of prodromal dementia (Ismail et al., 2018; Taragano et al., 2018; Creese et al., 2019). While NPSs impair the quality of life of both patient and caregiver, they seem to exert the strongest impact on the latter (Feast et al., 2016; Terum et al., 2017) and may influence the decision regarding nursing home placement (Porter et al., 2016; Vandepitte et al., 2018). In addition, together with the severity of dementia, the presence of NPS contributes to increasing care costs (Rattinger et al., 2015; Wübker et al., 2015; Rattinger et al., 2019).

NPS have a high prevalence index, and different patterns of symptoms are observed depending on the course of the illness, biological factors, diagnosis, age of onset, dementia severity, and place of residence of patients (Lyketsos et al., 2000; Tractenberg et al., 2003; Ryu et al., 2005; Ballard, 2007; Peters et al., 2012; van der Linde et al., 2012; Borsje et al., 2015; Mulders et al., 2016; van der Linde et al., 2016; Bauhuis et al., 2018; Rozum et al., 2019). A good example is $\mathrm{AD}$, in which NPS are extremely common: apathy is the most frequent symptom, followed by depression, aggression, anxiety, and sleep disorder (Zhao et al., 2016). Other symptoms, such as irritability, appetite disorder, aberrant motor behavior, delusion, disinhibition, and hallucination are less common, with their prevalence ranging from 36 to $16 \%$ of $\mathrm{AD}$ cases. Therefore, it is necessary to implement effective strategies against NPS and their unavoidable serious consequences.

The aim of the paper is to review current knowledge, limitations, and practices regarding the management of BPSD and to discuss on-going clinical trials and future therapeutic options.

\section{REVIEW OF CURRENT KNOWLEDGE ON BPSD MANAGEMENT}

\section{Non-Pharmacological Strategies}

A number of non-pharmacological techniques are used in medicine, specifically in the late-life population, a number of which have been found to be effective at treating neuropsychiatric symptoms (Gitlin et al., 2009; Abraha et al., 2017); however, the quality of evidence for such interventions is low (Wang G. et al., 2018), and there is limited evidence for recommending their use in general (Cabrera et al., 2015). As recent papers on non-pharmacological interventions have higher reporting quality than older ones, it is likely that our knowledge on the role of non-pharmacological interventions will be steadily improved as more studies are performed (Horr et al., 2015).

Non-pharmacological approaches comprise various types of intervention: sensory stimulation (acupressure, aromatherapy, massage, touch therapy, light therapy, garden activities, music and dance therapy, and snoezelen multisensory stimulation therapy), cognitive and emotion-oriented approaches (cognitive stimulation, reminiscence therapy, validation therapy, and simulated presence therapy), behavior management techniques, multicomponent interventions, and other therapies (education of patients and caregivers, exercise, and animal-assisted therapy involving real or robotic animals) (Abraha et al., 2017). Non- pharmacological strategies were even found to be more effective than pharmacological treatments (Yury and Fisher, 2007; Brodaty and Arasaratnam, 2012; Schneider et al., 2006a) and appear to have fewer adverse effects than pharmacotherapy with antipsychotics (Dyer et al., 2018). Moreover, a meta-analysis found such interventions to prove useful, versatile, and potentially cost-effective in improving outcomes and quality of life in individuals with dementia and their carers (Olazarán et al., 2010).

However, in practice, the widespread use of nonpharmacological strategies is beset by many difficulties, the main ones being lack of trained personnel, limited knowledge on the efficacy of nonpharmacological interventions, staff opinions and preferences, and an expectation of quick resolution of symptoms (Ervin et al., 2014; Jennings et al., 2018). In addition, in the case of severe agitation, or other emergency situations where patients may be endangering themselves or others, pharmacological intervention has priority. In typical situations, current evidence suggests that nonpharmacological techniques should be used as a first-line option for NPS and that many clinical guidelines recommend starting with such management (Dyer et al., 2018).

This part of the review will focus on recent advancements in non-pharmacological management (NPM) and discuss other approaches a reader can find in previous works (see Meyer and O'Keefe, 2018).

As NPM supports mainstream therapy in alleviating symptoms and improving the quality of life of patients, both approaches should be considered as parts of a broader concept of person-centered care (PPC). PPC, by supporting the personhood of patients and understanding their experience, attempts to assist them and their family in reaching the best possible quality of life (Molony et al., 2018).

The well-being of a patient with dementia can be achieved through understanding the individual needs and history of each patient. Similarly, to successfully reduce its occurrence, the underlying cause of the symptom also has to be understood. NPS can stem either from neurocognitive impairment associated with dementia or from the unmet needs of the patient; therefore, the possible interplay between these factors should be addressed while planning intervention.

In cases of dementia where cognitive functions are impaired, patients lose their ability to communicate through language. In such cases, they can sill manifest their needs, such as pain, hunger, boredom, insecurity, or anxiety, through their behavior. However, such behavior may be influenced by their cognitive impairment, which affects the way they perceive, interpret, and react to the environment: patients may have problems with explicit memory, recognition of visual motion or spatial orientation, and topographic disorientation (Zwijsen et al., 2016). A greater understanding of the mechanisms underpinning behavior can serve as a basis for more precise interventions.

Non-pharmacological interventions can be divided into direct ones targeted at patients and indirect ones targeted at their environment (Caspar et al., 2018). 
Direct interventions attempt to address the needs of the patient and can include lifestyle modification (e.g., diet, activity programs) or psychological therapy (art therapy, humor, animal, or PARO robotic pets assisted therapy); in contrast, indirect interventions involve either modification of the physical environment such as room temperature, light and noise levels, or familiarity or educating caregivers and reducing the stress and burden placed on them (Marriott et al., 2000; Soril et al., 2014).

One of the most distressing symptoms for caregivers is agitation, or aggression, which also is one of the most common reasons for antipsychotic prescription. However, antipsychotic use is associated with a high risk of adverse effects (Farlow and Shamliyan, 2017), and there is an urgent need to define efficient strategies to reduce their occurrence.

Between 45 and $80 \%$ of patients with dementia in nursing homes suffer from chronic pain. Impaired cognitive functions limit the possibility of communicating pain and thereby increase the risk of this pain of being underdiagnosed and untreated (Hadjistavropoulos et al., 2007). Similarly, lack of activity concerns up to $90 \%$ of patients with dementia residing in nursing homes: A problem that has been consequently raised by researchers since 1995 (Nolan et al., 1995; Hancock et al., 2006). Pain and boredom are important determinants of agitation (Kolanowski et al., 2017), and interventions directing them have been explored as a potential way to lower the level of agitation. In one study, nursing home residents were visited by a pair of elder-clowns for approximately $10 \mathrm{~min}$, twice a week, for 12 weeks. The clowns interacted with the patients using improvisation, humor, empathy, and expressive modalities such as songs, musical instruments, and dance. At the end of the intervention, the total NPI-NH scores were found to have declined significantly, and a general reduction of agitation was observed (Kontos et al., 2016).

In another study, a group of patients treated with 8 weeks of pain management demonstrated significantly lower agitation and aggression in comparison with controls (Husebo et al., 2011; Husebo et al., 2014).

PARO robotic pets, in use since 2003, have proven successful in lowering stress, depression, and anxiety in patients with dementia. Intervention with a robotic pet three times weekly per $20 \mathrm{~min}$ was found to reduce the need for pain medications and psychoactive medication (Petersen et al., 2017).

No significant improvement in total NPI score was observed after 3 months of supplementation with nutraceutical formulation (NF) [folate, alpha-tocopherol, B12, S-adenosyl methionine (SAM) N-acetyl cysteine (NAC), and acetyl-Lcarnitine (ALCAR)] as part of the Phase II Randomized Clinical Trial of a Nutritional Formulation for Cognition and Mood in Alzheimer's Disease (Remington et al., 2015).

Another group of interventions are those that directly focus on supporting the identity of the patients with dementia. In 2011, Caddell and Clare reviewed existing interventions and identified 10 studies aimed at promoting the preservation of patient identity. Although all interventions reported benefits to the patients, the considerable heterogeneity of patients and methodologies used in the study do not allow any firm conclusions to be drawn (Caddell and Clare, 2011). A promising area of research attempts to enhance and enrich the strategies used by patients to cope with cognitive impairment to promote well-being in the early stages of dementia. The spectrum of responses to problems with memory has been proposed to range from 'self-maintaining' to 'self-adjusting' (Clare, 2003). While patients following a self-maintaining strategy attempt to maintain the prediagnosis concept of self, those with a self-adjusting stance adapt a self-concept based on the challenges associated with the memory decline. A Preserving Identity and Planning for Advance Care (PIPAC) intervention combines these two components. The self-maintaining (reminiscence-based) component includes documenting an identity-salient role from the life history of the patient with the aim of describing what it meant to patients to "live well" in the past. The self-adjusting component is incorporated into a discussion of advance care planning (ACP), in which the patients focus on what it means for them to 'live well' in the future. They are informed about treatment options and how care decisions are made and rehearse communicating their preferences to relatives. After intervention, authors observed lower depressive symptoms and illness burden and greater quality of life and health-related indicators of well-being (Hilgeman et al., 2014).

Studies suggest that a combination of both direct and indirect non-pharmacological interventions may be essential in order to alleviate BPSD. Moreover, a recent study on health-related quality of life (HRQL) for people with dementia found antipsychotic discontinuation to have a detrimental effect on HRQL. This negative impact was, however, mitigated by social interactions (Ballard et al., 2017).

For intervention to be successful, it should consider the importance of a caring environment, i.e., the physical, built one, and the social environment, as well as care skill development and maintenance, and taking an individualized approach to each patient (Caspar et al., 2018).

\section{Pharmacological Treatments}

Currently, non-pharmacological and pharmacological management options exist for treating NPSs. Of the two, pharmacological intervention seems to be the ideal solution, mainly from the perspective of the caregiver. Oral dosage form administration is quick and easier than non-pharmacological interventions; in addition, it does not require professional staff involvement and allows the strength of the effect to be changed by increasing the dose of the drug. Moreover, in real life, some caregivers are interested in the possibility of administering the drug in the form of a solution without informing the patient.

Pharmacological interventions have many limitations in specific populations such as elderly patients with dementia and behavioral symptoms.

A key problem is the relatively small number of randomised clinical trials, most of which have been carried out on a narrowly defined indication, such as apathy, depression, or anxiety: some publications employ general terms such as psychiatric symptoms, while others use very detailed ones such as apathy in patients 
with Huntington's disease. Neuropsychiatric symptoms, on the other hand, occur in the majority of types of dementia, not just Alzheimer's disease (AD). In addition to AD, studies on DLB, PDD and frontotemporal lobe degeneration have also been performed; however, many of the observations on the efficacy of psychotropics in behavioral changes are based on studies conducted in other age groups with different clinical charactristics. Most research focuses on the effectiveness of antipsychotics, mood stabilizers and antidepressants in treating NPSs, and cholinesterase inhibitors and memantine in the case of AD.

Only few drugs are indicated for treating NPSs in dementia. Tiapride is recommended for agitation in cases with dementia in Poland, and pimavanserin for psychosis associated with Parkinson's disease in the USA. In addition, risperidone is recommended for treating persistent aggression in moderateto-severe cases of $\mathrm{AD}$ not responding to non-pharmacological interventions and when there is a risk of harm to the patient; however, treatment should be restricted to 6 weeks (Canada and Europe). Finally, quetiapine is recommended for psychiatric symptoms in patients with dementia; this indication is covered by public insurance in Poland (Lanctôt et al., 2017). Although prescribing psychotropic medications to a patient with dementia appears to be clinically justified, it still remains an off-label order in most countries.

Secondly, a minority of interventions with psychotropic drugs for NPSs in nursing homes is fully appropriate (van der Spek et al., 2016). A difference between correctness of use of antidepressants (used mostly appropriately) and anticonvulsants (used mostly inappropriately) was noticed. Unfortunately, for many (frequently unclear) reasons, the main method of pharmacological treatment of NPSs is based on antipsychotics. Antipsychotics are disproportionately often used in older populations (Colenda et al., 2002; Nijk et al., 2009; Gulla et al., 2016; Maust et al., 2017) for various indications, not only psychosis. Many physicians believe that antipsychotics are multipotential: they may also be effective in other clinical conditions, and their primary activity does not conern psychoses. Therefore, their prescription is reasonable in patients with delusions, hallucinations, or psychotic anxiety (Sultzer et al., 2008). Even if prescribing a neuroleptic to a person with dementia appears to be clinically justified, it still remains an off-label order in most countries (Maglione et al., 2011). In many cases, neuroleptics act mainly via a non-specific sedative effect and serve as a form of chemical restraint: efficacy data indicates that for all atypical antipsychotics show at best modest benefit against neuropsychiatric symptoms observed in cases with dementia (Seitz et al., 2013).

Thirdly, antipsychotics have been consistently associated with serious adverse effects and increased mortality in patients with dementia (Schneider et al., 2005; Ma et al., 2014; Schneider et al., 2006a; Kales et al., 2012; Ralph and Espinet, 2018), with the risk being dose-dependent (Maust et al., 2015). Increased mortality is related to a range of interacting factors, and the precise mechanisms of death are still uncertain. Antipsychotic treatment can result in cerebrovascular events (e.g., stroke), cardiovascular effects (e.g., orthostatic hypotension, cardiac arrhythmias, and QTc prolongation), metabolic effects, extrapyramidal symptoms and falls, as well as pneumonia (Steinberg and Lyketsos, 2012).

The growing body of evidence regarding the increased risk related to antipsychotic use among patients with dementia resulted in black box warnings being issued by the FDA for atypical drugs (in 2005) and conventional drugs (in 2008), and as experts' recommendations (Herrmann et al., 2013; Ihl et al., 2015). However, these guidelines have had little impact on prescribing psychotropics in some practices (Desai et al., 2012; Craig et al., 2016) and with positive trends in others, such as Danish residents aged $\geq 65$ years (Nørgaard et al., 2016). The drug may often be prescribed in response to the request of a care giver, family member, or member of staff.

Finally, overuse of antipsychotics has been reported (Rios et al., 2017), and some measures for limiting such practices have been undertaken (Jessop et al., 2017; Kirkham et al., 2017).

However, while long-term antipsychotic treatment is known to be associated with an increased risk of mortality, their use may be justified by circumstances. Even if the decision to implement the treatment may be clinically justified, regular attempts to withdraw these drugs are recommended in guidelines (Azermai et al., 2012), and practical algorithms have been proposed for process of drug discontinuation (Miarons et al., 2017). Even so, withdrawal of these drugs has consequences, especially after long-term use, including the obvious risk of re-aggravation of NPSs. A meta-analysis published by Declercq et al. indicates that $\mathrm{AD}$ patients can be withdrawn from chronic antipsychotic medication without demonstrating detrimental effects on their behavior (Declercq et al., 2013); however, the precise effects of withdrawal on patient cognition, adverse events, quality of life, and decrease in mortality remain unknown (Van Leeuwen et al., 2018).

\section{Agitation}

Agitation is quite a common problem in patients with Alzheimer-type dementia but may also occur in other types of dementing illnesses. Although non-pharmacological treatments represent first-line options, they are often of limited efficacy. This fact may explain why various categories of psychotropic drugs are used for treatment of agitation in dementia. These include typical (promazine) and atypical antipsychotics, antidepressants, anticonvulsants, antihistaminergic drugs (hydroxyzine), and herbal preparations. Most of these are off-label psychotropic medications, because there is insufficient or no data for their efficacy and safety in patients with dementia, and their prescription is based on tradition and personal opinions of physicians. Most worryingly, their use may entail serious adverse effects (SAEs). For example, a recent Cochrane metaanalysis (Baillon et al., 2018) suggests that valproate preparations, which are widely used for "organic brain disorders", may well be ineffective at treating agitation in people with dementia. The treatment has a high rate of adverse effects, associated with possible SAEs, and hence valproate cannot be recommended for management of agitation in dementia. 
Few papers have been published on the efficacy of antidepressants in agitation and psychosis in patients with dementia. A Cochrane meta-analysis concluded that the citalopram and sertraline were more effective in reducing symptoms of agitation compared to placebo in two studies (Seitz et al., 2011). SSRIs and trazodone were also found to be well tolerated when compared to typical and atypical antipsychotics. In addition, no differences were observed between antidepressants and typical or atypical antipsychotics in terms of efficacy.

A recent systematic review and meta-analysis of RCTs performed to determine the most efficacious and acceptable treatments of agitation in dementia found that haloperidol demonstrated little efficacy compared to placebo, despite its relatively widespread use for alleviating agitation (Kongpakwattana et al., 2018). In addition, dextromethorphan/ quinidine and risperidone were significantly more efficacious than placebo, as were SSRIs when considered as a class, but not when analyzed individually.

Moreover, some completed randomized controlled trials (RCTs) on treating agitation in dementia of Alzheimer-type with new or repositioned drugs have been published recently (Porsteinsson and Antonsdottir, 2017). Considering the available data on drug efficacy, adverse effects, availability, and novel drug registration procedures, it seems that citalopram may be the most sensible option for many physicians in controlling agitation in $\mathrm{AD}$ (Porsteinsson et al., 2014). However, the treatment period should be at least nine weeks long to allow enough time for full response (Weintraub et al., 2015). An alternate algorithm of drug treatment for agitation and aggression associated with $\mathrm{AD}$ or mixed dementia was proposed by Davies et al. (2018). The authors recommend starting treatment with risperidone, then aripiprazole or quetiapine, followed by carbamazepine and then citalopram. In the case of citalopram prescription, it is important to be aware of the increased risk of QTc prolongation, which can be problematic in geriatric patients. Promising novel and/or repositioned drugs intended for agitation in dementia are characterized in Tables $\mathbf{1}$ and $\mathbf{2}$.

An alternative method of treating agitation in dementia is by electroconvulsive therapy (ECT). A recent review of papers investigating the use of ECT for treating agitation in dementia (Glass et al., 2017) identified 11 papers, with a total number of 216 patients. The studies indicate promising results in decreasing agitation in patients with dementia; however, the studies have many methodological limitations regarding the type of study, use of psychotropic medications, choice of scales, lack of control group and numer of patients, among others.

\section{Psychotic Features}

Most psychosis symptoms that occur in dementia are hallucinations and delusions, and many patients require antipsychotic treatment to deal with of such distressing psychiatric symptoms. This is especially true when a patient acts on the delusions, experiences significant fear, or if their safety is threatened.

Antipsychotics are still widely prescribed, even in cases of dementia without psychosis. While a decline of first generation antipsychotic drug prescriptions was observed following a UK National Guidance and Drug Safety Warning, by the National Institute for Health and Care Excellence, the decreasing trend in second-generation drug prescriptions has been halted by the increased prescription of risperidone (Stocks et al., 2017).

In 2016, the American Psychiatric Association published a set of Practice Guidelines on the use of antipsychotics to treat agitation or psychosis in dementia (Reus et al., 2016). The guidelines comprise 15 statements on antipsychotic use in dementia, grouped into five sections: assessment of behavioral/ psychological symptoms of dementia; development of a comprehensive treatment plan; assessment of benefits and risks of antipsychotic treatment for the patient; dosing, duration, and monitoring of antipsychotic treatment; and use of specific antipsychotic medications depending on clinical context. Although Reus et al. (2016) indicate that "guidelines should not be considered as a statement of the standard of care or inclusive of all proper treatments or methods of care", such guidance regarding the method of assessing the need for antipsychotic treatment and monitoring results may nevertheless be of value to clinicians.

The efficacy and safety of the antipsychotics olanzapine, quetiapine, and risperidone in treating dementia were examined in the CATIE-AD study (Ismail et al., 2007; Sultzer et al., 2008; Schneider et al., 2006b). Other second-generation antipsychotics, such as aripiprazole and ziprasidone, have also demonstrated safety and efficacy in treating AD (De Deyn et al., 2005; Rocha et al., 2006; Mintzer et al., 2007; Streim et al., 2008), as well as in dementia with Lewy Bodies (Lee and Shen, 2017; Sugawara Kikuchi and Shimizu, 2019), where neuroleptic treatment is problematic due to neuroleptic hypersensitivity.

Currently, more data is needed to conclusively determine whether different atypical antipsychotics vary with regard to their effectiveness, or their risk of mortality or cerebrovascular events (Yunusa et al., 2019). Novel drugs such as pimavanserin in synucleinopathies and brexiprazole are undergoing evaluation in various populations of patients with dementia (Table 1).

\section{Apathy}

Apathy is a non-cognitive symptom and one of the most prevalent behavioral and psychological symptoms of dementia, which can be observed even at the prodromal stage (Sherman et al., 2018). It can be characterized as diminished motivation or even lack of motivation and loss of initiative. Apathy is a longlasting state that is associated with increased mortality and a substantially greater burden for caregivers (Harrison et al., 2016; Camargo et al., 2016; Nijsten et al., 2017; Terum et al., 2017); however, a Japanese study found apathy, anxiety, and depression not to seriously aggravate caregiver burnout. A higher level of burnout was related to agitation/aggression, irritability, aberrant motor behavior, and hallucinations (Hiyoshi-Taniguchi et al., 2018).

Although our understanding of the underlying neuronal basis of apathy has improved in recent years, the effectiveness of treatment is still limited (Huey et al., 2017; Lansdall et al., 2017; Ducharme et al., 2018; Fernández-Matarrubia et al., 2018; Kumfor et al., 2018). The treatment of apathy includes 
TABLE 1 | Current studies on pharmacological treatment of agitation and psychosis in dementia with novel drugs [data available at: ClinicalTrials.gov (accessed June 30, 2020); filters used: agitation, psychosis, and dementia; Studies: recruiting; not yet recruiting; active, not recruiting; enrolling by invitation]; PLC, placebo; PD, Parkinson's disease; AD, Alzheimer's disease; FTD, fronto-temporal dementia.

Study

Treatment

Results/status of the study

Study ID

population

Pimavanserin A selective 5-hydroxytryptamine (HT)2A PD psychosis $\quad$ Pimavanserin $34 \mathrm{mg}$ vs. PLC receptor inverse agonist/antagonis

AD psychosis $\quad$ Pimavanserin $34 \mathrm{mg}$ vs. PLC

AD psychosis

Pimavanserin $34 \mathrm{mg}$ vs. PLC

Scyllo-inositol linhibition of amyloid beta peptide (ELND005) aggregation

\section{Mibampator An amino-3-hydroxy-5-methyl-4- (LY-451395) isoxazole propionic acid receptor} potentiator

psychosis

\section{PD psychosis A retrospective chart review}

Agitation and

aggression in $\mathrm{AD}$

agitation and

aggression in $A D$

Agitation and

aggression in $A D$

\section{Significant improvement with pimavanserin vs. PLC ACP-103-020; \\ $(-5.79$ decrease in SAPS-PD scores in pimavanserin (Cummings et al., \\ group compared with -2.73 for PLC (difference -3.06, 2014)}

$95 \% \mathrm{Cl}-4.91$ to $-1.20 ; \mathrm{p}=0.001$; Cohen's d 0.50))

Pimavanserin (34 mg and $20 \mathrm{mg}$ ) vs. PLC

A prospective, 12-week, Randomized, Double-Blind,

Placebo-Controlled, Phase 2 Efficacy and Safety

Study of Oral ELND005 for Treatment of Agitation and

36-week extension study of Study AG201

$3 \mathrm{mg}$ of mibampator orally twice daily for 12 weeks

(may have been reduced to $1 \mathrm{mg}$ if participant was unable to tolerate) vs PLC
Significant improvement for pimavanserin

Primary endpoint (week 6): Mean change in the

Neuropsychiatric Inventory-Nursing Home version

psychosis score

Pimavanserin versus PLC: -3.76 points (SE 0.65)

versus -1.93 points $(0.63)$ (mean difference -1.84

[95\% Cl -3.64 to -0.04], Cohen's d=-0.32; $p=0 \cdot 045$ );

No significant advantage for pimavanserin versus PLC

at week 12 (treatment difference -0.51 [95\% Cl -2.23

to $1 \cdot 21$ ]; $p=0 \cdot 561$ );

Significant efficacy in patients with higher baseline

severity of psychotic symptoms

(delta $=-4.43$, Cohen's $d=-0.73, p=0.011$ )

Pimavanserin vs PLC:

$\geq 30 \%$ improvement was $88.9 \%$ vs. $43.3 \%$

(p<0.001);

$250 \%$ improvement was

$77.8 \%$ vs. $43.3 \%$ ( $p=0.008)$;

No Study Results Posted on ClinicalTrials.gov for this Study;

Study has br

published:

Clinical improvement in psyc

ACP-103-019; (Ballard et al., 2018)

ACP-103-019; (Ballard et al., 2019)

NCT03325556; [ACP103-045]; 2017-

002227-13 (EudraCT

Number)

(Sellers et al., 2019)

$76 \%$ of patients $(69 / 91)$

Study has been completed, results have not been NCT01735630;

published;

ELND005-AG20

Study has been terminated, results have not been

published;

Study Results have been posted on ClinicalTrials.gov;

No significant group differences:

mibampator was significantly better $(p=0.007)$ than PLC only on the Frontal Systems Behavior Inventory 


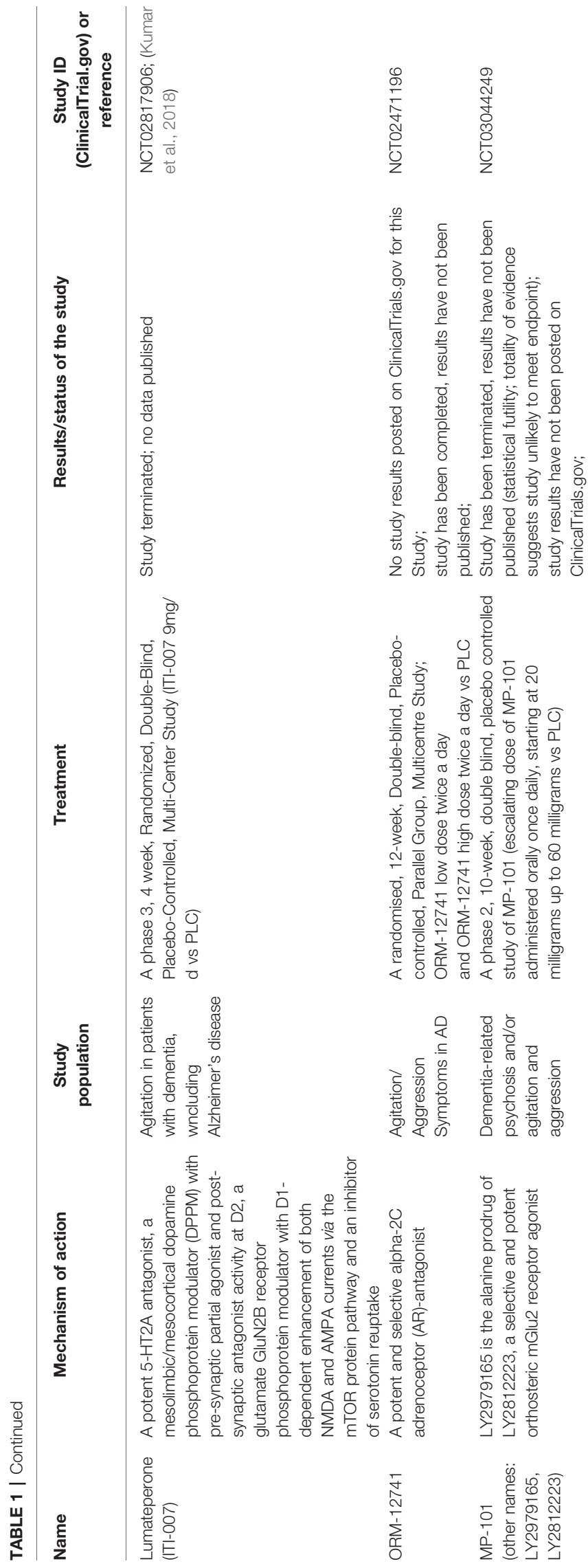

both non-pharmacological and pharmacological strategies and varies according to the type of dementia. A number of nonpharmacological interventions have been employed: musicbased interventions, regular individualized one-on-one personal contact, the use of cognitive stimulation therapy, multi-sensory behavior therapy, behavioral and environmental interventions, group art therapy, the use of therapeutic conversation, reminiscent group therapy, and Snoezelen-based care (Goris et al., 2016). However, a review of existing evidence shows it to be an underexplored field (Theleritis et al., 2018).

Cholinesterase inhibitors, memantine, antidepressants, antipsychotics, psychostimulants, and drugs with various mechanisms of action have demonstrated mixed results or no efficacy at all for treating apathy in Alzheimer's disease (Sepehry et al., 2017; Ruthirakuhan et al., 2018). Agomelatine, but not paroxetine, was associated with a significant reduction of apathy in FTD (Deakin et al., 2004; Callegari et al., 2016), while bupropion was ineffective in the treatment of apathy in Huntington's disease (Gelderblom et al., 2017). Apathy is a substantial part of clinical picture of Parkinson's disease (den Brok et al., 2015), Parkinson's disease dementia, and dementia with Lewy bodies, significantly affecting the course of the disease in the case of the latter (Breitve et al., 2018). However, no efficatious treatment currently is known to exist (Santangelo et al., 2013; Holguín Lew et al., 2017).

\section{Depression}

Depression is inextricably linked to cognitive disorders and dementia. Over the years, there has been a discussion about the relationship between depression and dementia (Bennett and Thomas, 2014). On the one hand, it was postulated that depression is a risk factor or a causative factor of dementia. On the other hand, depression has been proven to be a typical presentation of the initial phases of dementia or MCI and is in fact part of the clinical picture of dementia. There is also a proposal that antidepressant treatment is responsible for the occurrence of dementia (Lee et al., 2016; Moraros et al., 2017; Wang C. et al., 2018), especially when inappropriate medication is ised (Heser et al., 2018). Regardless of neuropathological and pathophysiological conditions, depression during dementia is a significant clinical and therapeutic problem with serious consequences for the patients and caregivers.

As with all BPSD, the management of clinical depression should start with the optimization of dementia treatment. Unfortunately, while acetylcholinesterase inhibitors and memantine are effective in the symptomatic treatment of $\mathrm{AD}$, current evidence suggests that they have limited efficacy for the treatment of depressive symptoms in dementia. Furthermore, non-pharmacological treatments, which are a preferred initial approach for all NPSs, have limited evidence for depressive symptoms. However, a recent review identified five modifiable relevant factors related to depression in dementia among community-dwelling individuals: pain, neuropsychiatric symptoms, cognitive decline, social isolation, and quality of life; in addition, neuropsychiatric symptoms and quality of life were found to be modifiable factors for patients living in longterm care facilities (Kubo et al., 2019). The authors conclude that 
TABLE 2 | Current studies on pharmacological treatment of agitation and psychosis in dementia with repositioned drugs [data available at: ClinicalTrials.gov (accessed June 30, 2020); filters used: agitation, psychosis, and dementia; Studies: recruiting; not yet recruiting; active, not recruiting; enrolling by invitation]; PLC, placebo; PD, Parkinson's disease; AD, Alzheimer's disease; FTD, frontotemporal dementia .

Deuterated (d6)- Dextromethorphan - a low-affinity Ndextromethorphan/ methyl-D-aspartate receptor antagonist, quinidine (AVP-

786

$\sigma 1$ receptor agonist, serotonin and

norepinephrine reuptake inhibitor, and neuronal nicotinic $\alpha 3 \beta 4$ receptor antagonist;

Quinidine - an anti-arrhythmic agent blocking voltage-gated sodium channels, inhibitor of cytochrome P450 2D6; Quinidine increases the bioavailability of dextromethorphan and prolongs its effects

Brexpiprazole

(OPC-34712) Second generation antipsychotic

Prazosin Postsynaptic alpha-1 adrenoreceptor antagonist

Agitation in patients with A phase 3, 12-week, multicenter, randomized, double-blind

Alzheimer's type dementia placebo-controlled, parallel-design Study

(AVP-786 (Dose 1)

vs AVP-786 (Dose 1)

VS PLC)

Agitation in patients with A phase 3, multicenter, long-term, extension study for 56 weeks

Alzheimer's type dementia

Agitation in patients with A phase 3, 12-week, multicenter, randomized, double-blind,

Alzheimer's type dementia placebo-controlled Study

Agitation associated with A phase 3, 12-week, multicenter, randomized, double-blind, Alzheimer's type dementia

placebo-controlled, fixed-dose trial (three arms: Low Dose

Brexpiprazole Arm vs. High Dose Brexpiprazole Arm vs PLC)

Agitation associated with A phase 2/3 multicenter, placebo-controlled, randomized, double-

Alzheimer's type dementia blind, parallel-group Comparison Trial (brexpiprazole $1 \mathrm{mg}$ vs. brexpiprazole $2 \mathrm{mg}$ vs. PLC for 10-week treatment regimen)

The long-term safety and A 12-week, multicenter, active-treatment extension trial to evaluate

tolerability of oral

brexpiprazole in agitation brexpiprazole oral tablet $2 \mathrm{mg} /$ day vs. Oral tablet $3 \mathrm{mg} /$ day; taken

associated with

Alzheimer's type dementia

Agitation associated with

Alzheimer's type dementia

Disruptive agitation in $A D$

A multicenter, oncontrolled, open-label trial

of brexiprazole $1 \mathrm{mg}$ or $2 \mathrm{mg}$ for a 14 week treatment regimen

Oral prazosin hydrochloride capsules will be administered twice daly, with individualized doses up to a maximum of $4 \mathrm{mg}$ mid-morning and $6 \mathrm{mg}$ at bedtime, or matching PLC capsules

Agitation/aggression in AD Prazosin (drug was initiated at $1 \mathrm{mg} /$ day and increased up to $6 \mathrm{mg}$

Disruptive agitation in $A D$

Prazosin: $4 \mathrm{mg}$ capsules twice daily for 12 weeks vs. PLC capsules twice daily for 12 weeks

Dementia related agitation and aggression and $\mathrm{CB} 2$ tetracyclic antidepressant (NaSSA)
Noradrenergic and specific serotonergic

Agitation in dementia

Mirtazapine (cannabis oil containing $\Delta$ 9-Tetra-Hydrocannabinol $(\Delta 9-\mathrm{THC})$ and $\mathrm{CBD}$ and $1.5 \% \triangle 9$-THC. Each oil drop contains about $12 \mathrm{mg}$ CBD and $0.6 \mathrm{mg} \triangle 9-\mathrm{THC})$

A Pragmatic, Multi Centre, 12-week, Double-blind, Placebo Controlled Randomised Trial of mirtazapine vs. PLC. Participants then be followed up for 1 year after
A phase 2, Randomized, Double-blind, Placebo-controlled Trial Cannabidiol (CBD) in a 1:20 ratio and at a concentration of 30\%
Study ID

(ClinicalTrial.gov)

or reference

\section{Results/status of the study}

Ongoing (study is recruiting

NCT03393520 participants)

Ongoing (study is recruiting participants)

Study has been completed,

results have not been

published;

Ongoing (study is recruiting NCT03548584

participants

Ongoing (study is recruiting participants

Ongoing (study is recruiting participants)

Ongoing (study is recruiting participants)

Ongoing (active, not recruiting)

Prazosin was well tolerated and improved behavioral symptoms in patients with agitation/aggression in $\mathrm{AD}$ Study has been completed, results have not been

published;

study results have been

posted on ClinicalTrials.gov:

Ongoing (study is recruiting participants)

\section{NCT03328676}

Ongoing (active, no

NCT03031184 


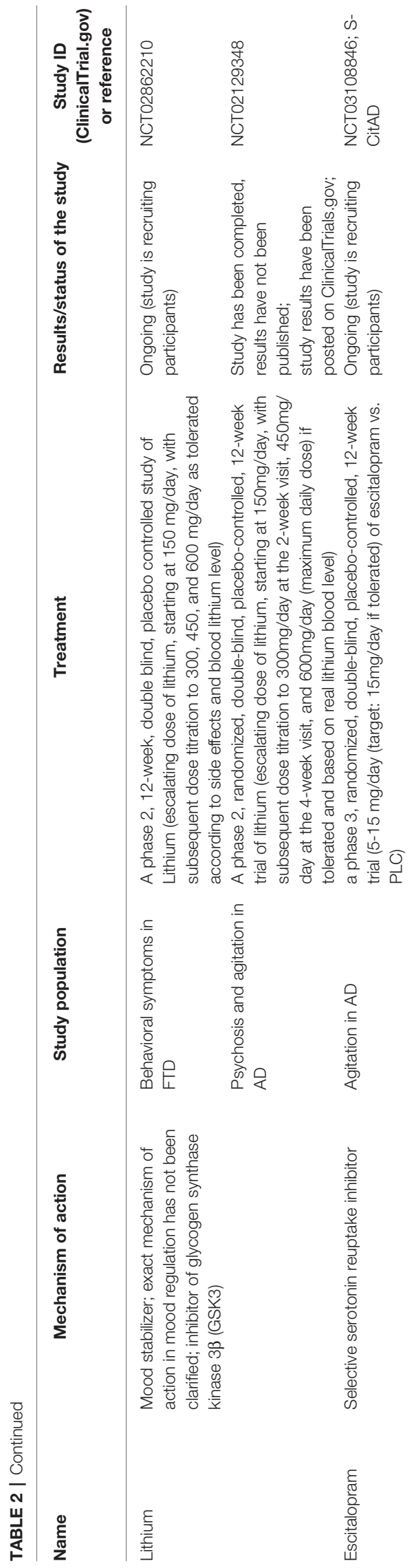

non-pharmacological interventions improving identified relevant factors may improve symptoms of depression in patients with dementia. Moreover, symptoms of depression and anxiety can be reduced by psychological interventions added to usual care (Orgeta et al., 2014; Orgeta et al., 2015).

While planning to implement non-pharmacological interventions for depression in patients with dementia, it should be considered that the presence of depression may be an important barrier to engagement in therapy, for example, physical activity (Watts et al., 2018).

In the majority of patients, however, pharmacological treatment is the basis of therapy.

A practical question arises whether there is sufficient evidence for recommending the use of pharmacotherapy in treating depression in patients with dementia (Farina et al., 2017; Ford and Almeida, 2017). Serotonergic drugs are a basic option in the treatment of mood disorders in the general population. It seems that they are also a good option for mood disorders in people with cognitive impairment and dementia (Magierski and Sobow, 2016). However, a recent Cochrane meta-analysis found little support for the efficacy of antidepressants for treating depression in dementia (Dudas et al., 2018).

\section{Sleep Problems}

Sleep disorders in patients with dementia are frequent, affecting between 25 and $80 \%$ of patients; these figures are higher than those associated with healthy aging and are believed to result from neurodegenerative processes (Ohayon et al., 2004; Bombois et al., 2010). The consequences of abnormal sleep in general population are increased risk of cognitive impairment and dementia (Bubu et al., 2017; Shi et al., 2018), but in patients with dementia, consequences include comorbidity, risk of falling, poorer quality of life, and increased psychological, physical, and financial burdens in the caregiver. In addition, sleep disorders are the primary risk factor for nursing home placement, even more so than cognitive impairment. Finally, they often aggravate the course of dementia through drowsiness during the day, thus impairing cognitive performance, driving, and social activities (Tractenberg et al., 2005).

Different sleep disorders are observed depending on the type of dementia (Roth, 2012). Alzheimer's disease is characterized by an irregular sleep-wake rhythm, sundowning, wandering, and obstructive sleep apnea. PDD is characterized by REM sleep behavior disorder, sleep maintance insomnia, hypersomnia, restless leg syndrome/periodic limb movements in sleep, while DLB patients demonstrate REM sleep behavior disorder, hypersomnia, periodic limb movements in sleep, and irregular sleep-wake rhythms. Similarly, those observed in FTDs include insomnia, excessive daytime sleepiness, sleep disordered breathing, and less frequent restless leg syndrome (McCarter et al., 2016).

It is difficult, or even impossible, to propose a universal method of treating sleep disorders in dementia due to this significant variation in clinical picture and neuropathology. Popular drugs for sleep disturbances in dementia include melatonin, trazodone, benzodiazepines, Z-drugs (zolpidem, zopiclone, and zaleplon), and recently registred ramelteon. At this point, it is necessary to recall that elderly benzodiazepine users became more sensitive to their medications. Paradoxical 
excitement (increased anxiety, acute excitement, and hyperactivity) can be observed in some cases. Moreover, the Z-drugs have documented night time unrecalled events, which may endanger other residents, and ramelteon may have a delayed onset for therapeutic effects of days. Other treatment modlaities include antihistaminergic drugs, herbal preaprations, or antidepresants (for example, mianserine and mirtazapine). A Cochrane metaanalysis examining the efficacy of pharmacotherapies for sleep disturbances in dementia found a lack of evidence regarding the issue of sleep problems in dementia (McCleery et al., 2016).

\section{NETWORK META-ANALYSES FOR PHARMACOLOGICAL AND NON- PHARMACOLOGICAL TREATMENTS OF BPSD}

A sizable numer of papers have been published on the effectiveness of different strategies targeting BPSD. As a result, both pharmacological and non-pharmacological methods are recommended through guidelines. Due to the diversity and extensiveness of interventions (exercise versus reminiscence therapy versus antipsychotic use) and the lack of head-to-head trials, it is difficult or even impossible to synthesize and objectify present data. This applies especially to descriptive literature reviews. Network meta-analysis solves this problem, because it allows findings to be analyzed quantitatively and for direct and indirect evidence to be evaluated simultaneously.

Several systematic reviews and network meta-analyses on the efficacy of different strategies for BPSD treatment were published recently. These publications examine the effectiveness of various therapeutic options and make head-to-head comparisons of the effectiveness of the tested drugs (Kongpakwattana et al., 2018).

A comparison of pharmacological and nonpharmacological interventions for treating aggression and agitation in adults with dementia (Watt et al., 2019) found showed that multidisciplinary care, massage and touch therapy, and music combined with massage and touch therapy were clinically more efficacious than usual care. Despite the study limitations, including high risk of bias related to outcome missing data, it was found that nonpharmacological interventions seemed to be more efficacious than pharmacological interventions for reducing aggression and agitation in adults with dementia. However, the study did not evaluate the harm and costs of the analyzed therapies. The effectiveness of non-pharmacological methods in managing of agitation in patients with dementia has also been confirmed elsewhere (Leng et al., 2020).

Another assessment of the comparative efficacy and safety of pharmacological and non-pharmacological therapies for treating BPSD (Jin and Liu, 2019) based on data from 146 randomized trials comprising 44,873 patients found that the antipsychotics aripiprazole, haloperidol, quetiapine, and risperidone demonstrated significant efficacy compared to placebo, while memantine, galantine, and donepezil have had the least. Importantly, all drugs were found to demonstrate acceptable safety, and the authors conclude that drug therapy should be the first option in the treatment of BPSD.

Similar results were obtained from a Bayesian network metaanalysis on the efficacy of cholinesterase inhibitors in patients with mild-to-moderate AD by Kobayashi et al. (2016) who conclude that ChEIs should have significant efficacy for cognition and global change assessment, but the efficacy on BPSD is questionable.

\section{PROMISING THERAPEUTIC OPTIONS OF BPSD}

As current strategies for the management of NPSs often lack effectifveness, there is a need to identify other treatment options. Although most studies focus on pharmacological interventions, some involve techniques known for their efficacy in a other clinical field. Noninvasive brain stimulation methods such as repetitive transcranial magnetic stimulation, (rTMS) and transcranial direct current stimulation (tDCS) have been tested in depression, schizophrenia, autism, and cognitive deficits in AD and MCI (Wei et al., 2017; Barahona-Corrêa et al., 2018; Cruz Gonzalez et al., 2018; Osoegawa et al., 2018). A meta-analysis of randomized controlled trials found rTMS protocols to demonstrate efficacy but not tDCS (Vacas et al., 2018); however, both were found to demonstrate safety and tolerability in the studied population.

\section{SUMMARY}

BPSD are a significant problem in everyday clinical practice due to the prevalence, severity of symptoms, burden on the caregiver, and difficulties in treatment. Many existing clinical guides recommend the use of non-pharmacological methods as the first course of action, and that pharmacotherapy should be used as a secondary option or when there is severe presentation of symptoms. In practice, a range of drugs are used, although most are antipsychotics. Unfortunately, many of the pharmacological options lack strong evidence from clinical trials confirming their effectiveness, and many others are used as off-label treatments.

\section{AUTHOR CONTRIBUTIONS}

RM and TS determined the outline. RM, ES, and DR reviewed the literature and wrote the manuscript. TS and DR reviewed and approved the manuscript.

\section{FUNDING}

Swedish Research Council (Drn 2012-2291) by grants provided by the Stockholm County Council (ALF project) and CIMED. None of the sponsors had any involvement in the design of the study, the data collection or analysis, the writing of the report or the decision to submit the paper for publication. 


\section{REFERENCES}

Abraha, I., Rimland, J. M., Trotta, F. M., Dell'Aquila, G., Cruz-Jentoft, A., Petrovic, M., et al. (2017). Systematic review of systematic reviews of nonpharmacological interventions to treat behavioural disturbances in older patients with dementia. The SENATOR-OnTop series. BMJ Open 7 (3), e012759. doi: 10.1136/bmjopen-2016-012759

Azermai, M., Petrovic, M., Elseviers, M. M., Bourgeois, J., Van Bortel, L. M., and Vander Stichele, R. H. (2012). Systematic appraisal of dementia guidelines for the management of behavioural and psychological symptoms. Ageing Res. Rev. 11 (1), 78-86. doi: 10.1016/j.arr.2011.07.002

Baillon, S. F., Narayana, U., Luxenberg, J. S., and Clifton, A. V. (2018). Valproate preparations for agitation in dementia. Cochrane Database Syst. Rev. 10, CD003945. doi: 10.1002/14651858.CD003945.pub4

Ballard, C., Orrell, M., Sun, Y., Moniz-Cook, E., Stafford, J., Whitaker, R., et al. (2017). Impact of antipsychotic review and non-pharmacological intervention on health-related quality of life in people with dementia living in care homes: WHELD - a factorial cluster randomised controlled trial. Int. J. Geriatr. Psychiatry 32, 1094-1103. doi: 10.1002/gps.4572

Ballard, C., Banister, C., Khan, Z., Cummings, J., Demos, G., Coate, B., et al. (2018). Evaluation of the safety, tolerability, and efficacy of pimavanserin versus placebo in patients with Alzheimer's disease psychosis: a phase 2, randomised, placebo-controlled, double-blind study. Lancet Neurol. 17 (3), 213-222. doi: 10.1016/S1474-4422(18)30039-5

Ballard, C., Youakim, J. M., Coate, B., and Stankovic, S. (2019). Pimavanserin in Alzheimer's Disease Psychosis: Efficacy in Patients with More Pronounced Psychotic Symptoms. J. Prev. Alzheimers Dis. 6 (1), 27-33. doi: 10.14283/ jpad.2018.30

Ballard, C. (2007). Agitation and psychosis in dementia. Am. J. Geriatr. Psychiatry 15 (11), 913-917. doi: 10.1097/JGP.0b013e3181584268

Barahona-Corrêa, J. B., Velosa, A., Chainho, A., Lopes, R., and Oliveira-Maia, A. J. (2018). Repetitive Transcranial Magnetic Stimulation for Treatment of Autism Spectrum Disorder: A Systematic Review and Meta-Analysis. Front. Integr. Neurosci. 12, 27. doi: 10.3389/fnint.2018.00027

Bauhuis, R., Mulders, A. J. M. J., and Koopmans, R. T. C. M. (2018). The course of neuropsychiatric symptoms in institutionalized patients with young onset dementia. Aging Ment. Health 30, 1-6. doi: 10.1080/13607863.2018.1531379

Bennett, S., and Thomas, A. J. (2014). Depression and dementia: cause, consequence or coincidence? Maturitas 79 (2), 184-190. doi: 10.1016/ j.maturitas.2014.05.009

Bombois, S., Derambure, P., Pasquier, F., and Monaca, C. (2010). Sleep disorders in aging and dementia. J. Nutr. Health Aging 14 (3), 212-217. doi: 10.1007/ s12603-010-0052-7

Borsje, P., Wetzels, R. B., Lucassen, P. L., Pot, A. M., and Koopmans, R. T. (2015). The course of neuropsychiatric symptoms in community-dwelling patients with dementia: a systematic review. Int. Psychogeriatr. 27 (3), 385-405. doi: $10.1017 /$ S1041610214002282

Breitve, M. H., Brønnick, K., Chwiszczuk, L. J., Hynninen, M. J., Aarsland, D., and Rongve, A. (2018). Apathy is associated with faster global cognitive decline and early nursing home admission in dementia with Lewy bodies. Alzheimers Res. Ther. 10 (1), 83. doi: 10.1186/s13195-018-0416-5

Brodaty, H., and Arasaratnam, C. (2012). Meta-analysis of nonpharmacological interventions for neuropsychiatric symptoms of dementia. Am. J. Psychiatry 169 (9), 946-953. doi: 10.1176/appiajp.2012.11101529

Bubu, O. M., Brannick, M., Mortimer, J., Umasabor-Bubu, O., Sebastião, Y. V., Wen, Y., et al. (2017). Sleep, Cognitive impairment, and Alzheimer's disease: A Systematic Review and Meta-Analysis. Sleep 40 (1). doi: 10.1093/sleep/zsw032

Cabrera, E., Sutcliffe, C., Verbeek, H., Saks, K., Soto-Martin, M., Meyer, G., et al. (2015). Non-pharmacological interventions as a best practice strategy in people with dementia living in nursing homes. A systematic review. Eur. Geriatr. Med. 6, 134-150. doi: 10.1016/j.eurger.2014.06.003

Caddell, L. S., and Clare, L. (2011). Interventions supporting self and identity in people with dementia: A systematic review. Aging Ment. Health 15 (7), $797-$ 810. doi: $10.1080 / 13607863.2011 .575352$

Callegari, I., Mattei, C., Benassi, F., Krueger, F., Grafman, J., Yaldizli, Ö., et al. (2016). Agomelatine Improves Apathy in Frontotemporal Dementia. Neurodegener. Dis. 16 (5-6), 352-356. doi: 10.1159/000445873
Camargo, C. H. F., Serpa, R. A., Matnei, T., Sabatini, J. S., and Teive, H. A. G. (2016). The perception of apathy by caregivers of patients with dementia in Parkinson's disease. Dement. Neuropsychol. 10 (4), 339-343. doi: 10.1590/ s1980-5764-2016dn1004014

Caspar, S., Davis, E. D., Douziech, A., and Scott, D. R. (2018). Nonpharmacological Management of Behavioral and Psychological Symptoms of Dementia: What Works, in What Circumstances, and Why? Innov. Aging 2 (1), igy001. doi: 10.1093/ geroni/igy001

Clare, L. (2003). Managing threats to self: awareness in early stage Alzheimer's disease. Soc Sci. Med. 57 (6), 1017-1029. doi: 10.1016/S0277-9536(02)00476-8

Colenda, C. C., Mickus, M. A., Marcus, S. C., Tanielian, T. L., and Pincus, H. A. (2002). Comparison of adult and geriatric psychiatric practice patterns: findings from the American Psychiatric Association's Practice Research Network. Am. J. Geriatr. Psychiatry 10 (5), 609-617. doi: 10.1097/00019442200209000-00015

Craig, C., Tannenbaum, C., Ducruet, T., and Moride, Y. (2016). Patterns of antipsychotic use among community-dwelling elderly patients with dementia: impact of regulatory warnings. Med. Safe. Glo. Heal. 5 (129), 2. doi: 10.4172/ 2574-0407.1000129

Creese, B., Brooker, H., Ismail, Z., Wesnes, K. A., Hampshire, A., Khan, Z., et al. (2019). Mild Behavioral Impairment as a Marker of Cognitive Decline in Cognitively Normal Older Adults. Am. J. Geriatr. Psychiatry 27 (8), 823-834. doi: 10.1016/j.jagp.2019.01.215

Cruz Gonzalez, P., Fong, K. N. K., Chung, R. C. K., Ting, K. H., Law, L. L. F., and Brown, T. (2018). Can Transcranial Direct-Current Stimulation Alone or Combined With Cognitive Training Be Used as a Clinical Intervention to Improve Cognitive Functioning in Persons With Mild Cognitive Impairment and Dementia? A Systematic Review and Meta-Analysis. Front. Hum. Neurosci. 12, 416. doi: 10.3389/fnhum.2018.00416

Cummings, J., Isaacson, S., Mills, R., Williams, H., Chi-Burris, K., Corbett, A., et al. (2014). Pimavanserin for patients with Parkinson's disease psychosis: a randomised, placebo-controlled phase 3 trial. Lancet 383 (9916), 533-540. doi: 10.1016/S0140-6736(13)62106-6

Davies, S. J., Burhan, A. M., Kim, D., Gerretsen, P., Graff-Guerrero, A., Woo, V. L., et al. (2018). Sequential drug treatment algorithm for agitation and aggression in Alzheimer's and mixed dementia. J. Psychopharmacol. 32 (5), 509-523. doi: $10.1177 / 0269881117744996$

De Deyn, P., Jeste, D. V., Swanink, R., Kostic, D., Breder, C., Carson, W. H., et al. (2005). Aripiprazole for the treatment of psychosis in patients with Alzheimer's disease: a randomized, placebo-controlled study. J. Clin. Psychopharmacol. 25 (5), 463-467. doi: 10.1097/01.jcp.0000178415.22309.8f

Deakin, J. B., Rahman, S., Nestor, P. J., Hodges, J. R., and Sahakian, B. J. (2004). Paroxetine does not improve symptoms and impairs cognition in frontotemporal dementia: a double-blind randomized controlled trial. Psychopharmacol. (Berl.) 172 (4), 400-408. doi: 10.1007/s00213-003-1686-5

Declercq, T., Petrovic, M., Azermai, M., Vander Stichele, R., De Sutter, A. I. M., van Driel, M. L., et al. (2013). Withdrawal versus continuation of chronic antipsychotic drugs for behavioural and psychological symptoms in older people with dementia. Cochrane Database Syst. Rev. (3), CD007726. doi: 10.1002/14651858.CD007726.pub2.

den Brok, M. G., van Dalen, J. W., van Gool, W. A., Moll van Charante, E. P., de Bie, R. M., and Richard, E. (2015). Apathy in Parkinson's disease: A systematic review and meta-analysis. Mov. Disord. 30 (6), 759-769. doi: 10.1002/ mds. 26208

Desai, V. C., Heaton, P. C., and Kelton, C. M. (2012). Impact of the Food and Drug Administration's antipsychotic black box warning on psychotropic drug prescribing in elderly patients with dementia in outpatient and office-based settings. Alzheimers Dement. 8 (5), 453-457. doi: 10.1016/j.jalz.2011.08.004

Ducharme, S., Price, B. H., and Dickerson, B. C. (2018). Apathy: a neurocircuitry model based on frontotemporal dementia. J. Neurol. Neurosurg. Psychiatry 89 (4), 389-396. doi: 10.1136/jnnp-2017-316277

Dudas, R., Malouf, R., McCleery, J., and Dening, T. (2018). Antidepressants for treating depression in dementia. Cochrane. Database. Syst. Rev. 8, CD003944. doi: 10.1002/14651858.CD003944.pub2

Dyer, S. M., Harrison, S. L., Laver, K., Whitehead, C., and Crotty, M. (2018). An overview of systematic reviews of pharmacological and non-pharmacological interventions for the treatment of behavioral and psychological symptoms of 
dementia. Int. Psychogeriatr. 30 (3), 295-309. doi: 10.1017/S10416 10217002344

Ervin, K., Cross, M., and Koschel, A. (2014). Barriers to managing behavioural and psychological symptoms of dementia: staff perceptions. Collegian 21 (3), 201207. doi: 10.1016/j.colegn.2013.04.002

Farina, N., Morrell, L., and Banerjee, S. (2017). What is the therapeutic value of antidepressants in dementia? A narrative review. Int. J. Geriatr. Psychiatry 32 (1), 32-49. doi: 10.1002/gps.4566

Farlow, M. R., and Shamliyan, T. A. (2017). Benefits and harms of atypical antipsychotics for agitation in adults with dementia. Eur. Neuropsychopharmacol. 27 (3), 217-231. doi: 10.1016/j.euroneuro.2017.01.002

Feast, A., Moniz-Cook, E., Stoner, C., Charlesworth, G., and Orrell, M. (2016). A systematic review of the relationship between behavioral and psychological symptoms (BPSD) and caregiver well-being. Int. Psychogeriatr. 28 (11), 17611774. doi: 10.1017/S1041610216000922

Fernández-Matarrubia, M., Matías-Guiu, J. A., Cabrera-Martín, M. N., MorenoRamos, T., Valles-Salgado, M., Carreras, J. L., et al. (2018). Different apathy clinical profile and neural correlates in behavioral variant frontotemporal dementia and Alzheimer's disease. Int. J. Geriatr. Psychiatry 33 (1), 141-150. doi: 10.1002/gps.4695

Ford, A. H., and Almeida, O. P. (2017). Management of Depression in Patients with Dementia: Is Pharmacological Treatment Justified? Drugs Aging 34 (2), 89-95. doi: 10.1007/s40266-016-0434-6

Gelderblom, H., Wüstenberg, T., McLean, T., Mütze, L., Fischer, W., Saft, C., et al. (2017). Bupropion for the treatment of apathy in Huntington's disease: A multicenter, randomised, double-blind, placebo-controlled, prospective crossover trial. PLoS One 12 (3), e0173872. doi: 10.1371/journal.pone.0173872

Gitlin, L. N., Winter, L., Vause Earland, T., Adel Herge, E., Chernett, N. L., Piersol, C. V., et al. (2009). The Tailored Activity Program to reduce behavioral symptoms in individuals with dementia: feasibility, acceptability, and replication potential. Gerontologist 49 (3), 428-439. doi: 10.1093/geront/gnp087

Glass, O. M., Forester, B. P., and Hermida, A. P. (2017). Electroconvulsive therapy (ECT) for treating agitation in dementia (major neurocognitive disorder) - a promising option. Int. Psychogeriatr. 29 (5), 717-726. doi: 10.1017/ S1041610216002258

Goris, E. D., Ansel, K. N., and Schutte, D. L. (2016). Quantitative systematic review of the effects of non-pharmacological interventions on reducing apathy in persons with dementia. J. Adv. Nurs. 72 (11), 2612-2628. doi: 10.1111/jan.13026

Gulla, C., Selbaek, G., Flo, E., Kjome, R., Kirkevold, Ø., and Husebo, B. S. (2016). Multi-psychotropic drug prescription and the association to neuropsychiatric symptoms in three Norwegian nursing home cohorts between 2004 and 2011. BMC Geriatr. 16, 115. doi: 10.1186/s12877-016-0287-1

Hadjistavropoulos, T., Herr, K., Turk, D. C., Fine, P. G., Dworkin, R. H., Helme, R., et al. (2007). An interdisciplinary expert consensus statement on assessment of pain in older persons. Clin. J. Pain 23 (1 Suppl), S1-43. doi: 10.1097/ AJP.0b013e31802be869

Hancock, G. A., Woods, B., Challis, D., and Orrell, M. (2006). The needs of older people with dementia in residential care. Int. J. Geriatr. Psychopharmacol. 21 (1), 43-49. doi: 10.1002/gps.1421

Harrison, F., Aerts, L., and Brodaty, H. (2016). Apathy in Dementia: Systematic Review of Recent Evidence on Pharmacological Treatments. Curr. Psychiatry Rep. 18 (11), 103. doi: 10.1007/s11920-016-0737-7

Herrmann, N., Lanctôt, K. L., and Hogan, D. B. (2013). Pharmacological recommendations for the symptomatic treatment of dementia: the Canadian Consensus Conference on the Diagnosis and Treatment of Dementia 2012. Alzheimers Res. Ther. 5 (Suppl 1), S5. doi: 10.1186/alzrt201

Heser, K., Luck, T., Röhr, S., Wiese, B., Kaduszkiewicz, H., Oey, A., et al. (2018). Potentially inappropriate medication: Association between the use of antidepressant drugs and the subsequent risk for dementia. J. Affect. Disord. 226, 28-35. doi: 10.1016/j.jad.2017.09.016

Hilgeman, M. M., Allen, R. S., Snow, A. L., Durkin, D. W., DeCoster, J., and Burgio, L. D. (2014). Preserving Identity and Planning for Advance Care (PIPAC): preliminary outcomes from a patient-centered intervention for individuals with mild dementia. Aging Ment. Health 18 (4), 411-424. doi: 10.1080/13607863.2013.868403

Hiyoshi-Taniguchi, K., Becker, C. B., and Kinoshita, A. (2018). What Behavioral and Psychological Symptoms of Dementia Affect Caregiver Burnout? Clin. Gerontol. 41 (3), 249-254. doi: 10.1080/07317115.2017.1398797
Holguín Lew, J. C., Caamaño Jaraba, J., Gómez Alzate, A., Hidalgo López, C., Marino Mondragón, D. F., Restrepo Moreno, S., et al. (2017). [Pharmacological Treatment of Apathy in Parkinson's Disease: a Systematic Review of the Literature]. Rev. Colomb. Psiquiatr. 46 (Suppl 1), 9-17. doi: 10.1016/ j.rcp.2017.06.004

Horr, T., Messinger-Rapport, B., and Pillai, J. A. (2015). Systematic review of strengths and limitations of randomized controlled trials for nonpharmacological interventions in mild cognitive impairment: focus on Alzheimer's disease. J. Nutr. Health Aging 19 (2), 141-153. doi: 10.1007/ s12603-014-0565-6

Huey, E. D., Lee, S., Cheran, G., Grafman, J., and Devanand, D. P. (2017). Brain Regions Involved in Arousal and Reward Processing are Associated with Apathy in Alzheimer's Disease and Frontotemporal Dementia. J. Alzheimers Dis. 55 (2), 551-558. doi: 10.3233/JAD-160107

Husebo, B. S., Ballard, C., Sandvik, R., Nilsen, O. B., and Aarsland, D. (2011). Efficacy of treating pain to reduce behavioural disturbances in residents of nursing homes with dementia: cluster randomised clinical trial. BMJ 343 , d4065. doi: 10.1136/bmj.d4065

Husebo, B. S., Ballard, C., Cohen-Mansfield, J., Seifert, R., and Aarsland, D. (2014) The response of agitated behavior to pain management in persons with dementia. Am. J. Geriatr. Psychiatry 22 (7), 708-717. doi: 10.1016/ j.jagp.2012.12.006

Ihl, R., Bunevicius, R., Frölich, L., Winblad, B., Schneider, L. S., Dubois, B., et al. (2015). World Federation of Societies of Biological Psychiatry guidelines for the pharmacological treatment of dementias in primary care. Int. J. Psychiatry Clin. Pract. 19 (1), 2-7. doi: 10.3109/13651501.2014.961931

Ismail, M. S., Dagerman, K., Tariot, P. N., Abbott, S., Kavanagh, S., and Schneider, L. S. (2007). National Institute of Mental Health Clinical Antipsychotic Trials of Intervention Effectiveness- Alzheimer's Disease (CATIE-AD): baseline characteristics. Curr. Alzheimer. Res. 4 (3), 325-335. doi: 10.2174/ 156720507781077214

Ismail, Z., Gatchel, J., Bateman, D. R., Barcelos-Ferreira, R., Chantillon, M., Jaeger, J., et al. (2018). Affective and emotional dysregulation as pre-dementia risk markers: exploring the mild behavioral impairment symptoms of depression, anxiety, irritability, and euphoria. Int. Psychogeriatr. 30 (2), 185-196. doi: $10.1017 /$ S1041610217001880

Jennings, A. A., Foley, T., Walsh, K. A., Coffey, A., Browne, J. P., and Bradley, C. P. (2018). General practitioners' knowledge, attitudes, and experiences of managing behavioural and psychological symptoms of dementia: A mixedmethods systematic review. Int. J. Geriatr. Psychiatry. 33 (9), 1163-1176. doi: $10.1002 /$ gps.4918

Jessop, T., Harrison, F., Cations, M., Draper, B., Chenoweth, L., Hilmer, S., et al. (2017). Halting Antipsychotic Use in Long-Term care (HALT): a single-arm longitudinal study aiming to reduce inappropriate antipsychotic use in long-term care residents with behavioral and psychological symptoms of dementia. Int. Psychogeriatr. 29 (8), 1391-1403. doi: 10.1017/ S1041610217000084

Jin, B., and Liu, H. (2019). Comparative efficacy and safety of therapy for the behavioral and psychological symptoms of dementia: a systemic review and Bayesian network meta-analysis. J. Neurol. 266 (10), 2363-2375. doi: 10.1007/ s00415-019-09200-8

Kales, H. C., Kim, H. M., Zivin, K., Valenstein, M., Seyfried, L. S., Chiang, C., et al. (2012). Risk of mortality among individual antipsychotics in patients with dementia. Am. J. Psychiatry 169 (1), 71-79. doi: 10.1176/appi.ajp. 2011.11030347

Kirkham, J., Sherman, C., Velkers, C., Maxwell, C., Gill, S., Rochon, P., et al. (2017). Antipsychotic Use in Dementia. Can. J. Psychiatry 62 (3), 170-181. doi: $10.1177 / 0706743716673321$

Kobayashi, H., Ohnishi, T., Nakagawa, R., and Yoshizawa, K. (2016). The comparative efficacy and safety of cholinesterase inhibitors in patients with mild-to-moderate Alzheimer's disease: a Bayesian network meta-analysis. Int. J. Geriatr. Psychiatry 31 (8), 892-904. doi: 10.1002/gps.4405

Kolanowski, A., Boltz, M., Galik, E., Gitlin, L. N., Kales, H. C., Resnick, B., et al. (2017). Determinants of behavioral and psychological symptoms of dementia: A scoping review of the evidence. Nurs. Outlook 65 (5), 515-529. doi: 10.1016/ j.outlook.2017.06.006

Kongpakwattana, K., Sawangjit, R., Tawankanjanachot, I., Bell, J. S., Hilmer, S. N., and Chaiyakunapruk, N. (2018). Pharmacological treatments for alleviating 
agitation in dementia: a systematic review and network meta-analysis. $B r . J$. Clin. Pharmacol. 84 (7), 1445-1456. doi: 10.1111/bcp.13604

Kontos, P., Miller, K. L., Colobong, R., Palma Lazgare, L. I., Binns, M., Low, L. F., et al. (2016). Elder-Clowning in Long-Term Dementia Care: Results of a Pilot Study. J. Am. Geriatr. Soc 64 (2), 347-353. doi: 10.1111/jgs.13941

Kubo, Y., Hayashi, H., Kozawa, S., and Okada, S. (2019). Relevant factors of depression in dementia modifiable by non-pharmacotherapy: a systematic review. Psychogeriatrics 19 (2), 181-191. doi: 10.1111/psyg.12371

Kumar, B., Kuhad, A., and Kuhad, A. (2018). Lumateperone: a new treatment approach for neuropsychiatric disorders. Drugs Today (Barc.) 54 (12), $713-$ 719. doi: 10.1358/dot.2018.54.12.2899443

Kumfor, F., Zhen, A., Hodges, J. R., Piguet, O., and Irish, M. (2018). Apathy in Alzheimer's disease and frontotemporal dementia: Distinct clinical profiles and neural correlates. Cortex 103, 350-359. doi: 10.1016/j.cortex.2018.03.019

Lanctôt, K. L., Amatniek, J., Ancoli-Israel, S., Arnold, S. E., Ballard, C., CohenMansfield, J., et al. (2017). Neuropsychiatric signs and symptoms of Alzheimer's disease: New treatment paradigms. Alzheimers Dement. (N. Y.) 3 (3), 440-449. doi: 10.1016/j.trci.2017.07.001

Lansdall, C. J., Coyle-Gilchrist, I. T. S., Jones, P. S., Vázquez Rodríguez, P., Wilcox, A., Wehmann, E., et al. (2017). Apathy and impulsivity in frontotemporal lobar degeneration syndromes. Brain 140 (6), 1792-1807. doi: 10.1093/brain/awx101

Lee, C., and Shen, Y. C. (2017). Aripiprazole Improves Psychotic, Cognitive, and Motor Symptoms in a Patient With Lewy Body Dementia. J. Clin. Psychopharmacol. 37 (5), 628-630. doi: 10.1097/JCP.0000000000000769

Lee, C. W., Lin, C. L., Sung, F. C., Liang, J. A., and Kao, C. H. (2016). Antidepressant treatment and risk of dementia: a population-based, retrospective case-control study. J. Clin. Psychiatry 77 (1), 117-122. doi: 10.4088/JCP.14m09580

Leng, M., Zhao, Y., and Wang, Z. (2020). Comparative efficacy of nonpharmacological interventions on agitation in people with dementia: A systematic review and Bayesian network meta-analysis. Int. J. Nurs. Stud. 102, 103489. doi: 10.1016/j.ijnurstu.2019.103489

Liew, T. M. (2019). Symptom Clusters of Neuropsychiatric Symptoms in Mild Cognitive Impairment and Their Comparative Risks of Dementia: A Cohort Study of 8530 Older Persons. J. Am. Med. Dir. Assoc. 20 (8), 1054. doi: 10.1016/ j.jamda.2019.02.012

Lyketsos, C. G., Steinberg, M., Tschanz, J. T., Norton, M. C., Steffens, D. C., and Breitner, J. C. (2000). Mental and behavioral disturbances in dementia: findings from the Cache County Study on Memory in Aging. Am. J. Psychiatry 157 (5), 708-714. doi: 10.1176/appi.ajp.157.5.708

Ma, H., Huang, Y., Cong, Z., Wang, Y., Jiang, W., Gao, S., et al. (2014). The efficacy and safety of atypical antipsychotics for the treatment of dementia: a metaanalysis of randomized placebo-controlled trials. J. Alzheimers Dis. 42 (3), 915937. doi: 10.3233/JAD-140579

Magierski, R., and Sobow, T. (2016). Serotonergic drugs for the treatment of neuropsychiatric symptoms in dementia. Expert. Rev. Neurother. 16 (4), 375387. doi: $10.1586 / 14737175.2016 .1155453$

Maglione, M., Maher, A. R., Hu, J., Wang, Z., Shanman, R., Shekelle, P. G., et al. (2011). Off-Label Use of Atypical Antipsychotics: An Update [Internet] (Rockville (MD): Agency for Healthcare Research and Quality (US)). 2011 Sep. Report No.: 11-EHC087-EF.

Marriott, A., Donaldson, C., Tarrier, N., and Burns, A. (2000). Effectiveness of cognitive-behavioural family intervention in reducing the burden of care in carers of patients with Alzheimer's disease. Br. J. Psychiatry 176, 557-562. doi: $10.1192 /$ bjp.176.6.557

Maust, D. T., Kim, H. M., Seyfried, L. S., Chiang, C., Kavanagh, J., Schneider, L. S., et al. (2015). Antipsychotics, other psychotropics, and the risk of death in patients with dementia: number needed to harm. JAMA Psychiatry 72 (5), 438445. doi: 10.1001/jamapsychiatry.2014.3018

Maust, D. T., Langa, K. M., Blow, F. C., and Kales, H. C. (2017). Psychotropic use and associated neuropsychiatric symptoms among patients with dementia in the USA. Int. J. Geriatr. Psychiatry 32 (2), 164-174. doi: 10.1002/gps.4452

McCarter, S. J., St Louis, E. K., and Boeve, B. F. (2016). Sleep Disturbances in Frontotemporal Dementia. Curr. Neurol. Neurosci. Rep. 16 (9), 85. doi: 10.1007/s11910-016-0680-3

McCleery, J., Cohen, D. A., and Sharpley, A. L. (2016). Pharmacotherapies for sleep disturbances in dementia. Cochrane Database Syst. Rev. 11, CD009178. doi: 10.1002/14651858.CD009178.pub3
Meyer, C., and O'Keefe, F. (2018). Non-pharmacological interventions for people with dementia: A review of reviews. Dementia. doi: 10.1177/14713012 18813234

Miarons, M., Cabib, C., Barón, F. J., and Rofes, L. (2017). Evidence and decision algorithm for the withdrawal of antipsychotic treatment in the elderly with dementia and neuropsychiatric symptoms. Eur. J. Clin. Pharmacol. 73 (11), 1389-1398. doi: 10.1007/s00228-017-2314-3

Mintzer, J. E., Tune, L. E., Breder, C. D., Swanink, R., Marcus, R. N., McQuade, R. D., et al. (2007). Aripiprazole for the treatment of psychoses in institutionalized patients with Alzheimer dementia: a multicenter, randomized, double-blind, placebo-controlled assessment of three fixed doses. Am. J. Geriatr. Psychiatry 15 (11), 918-931. doi: 10.1097/JGP.0b013e3181557b47

Molony, S. L., Kolanowski, A. M., Van Haitsma, K. S., and Rooney, K. E. (2018). Person-Centered Assessment and Care Planning. Gerontologist 58, S32-S47. doi: 10.1093/geront/gnx173

Moraros, J., Nwankwo, C., Patten, S. B., and Mousseau, D. D. (2017). The association of antidepressant drug usage with cognitive impairment or dementia, including Alzheimer disease: A systematic review and metaanalysis. Depress. Anxiety 34 (3), 217-226. doi: 10.1002/da.22584

Mulders, A. J., Fick, I. W., Bor, H., Verhey, F. R., Zuidema, S. U., and Koopmans, R. T. (2016). Prevalence and Correlates of Neuropsychiatric Symptoms in Nursing Home Patients With Young-Onset Dementia: The BEYOnD Study. J. Am. Med. Dir. Assoc. 17 (6), 495-500. doi: 10.1016/j.jamda.2016.01.002

Nijk, R. M., Zuidema, S. U., and Koopmans, R. T. (2009). Prevalence and correlates of psychotropic drug use in Dutch nursing-home patients with dementia. Int. Psychogeriatr. 21 (3), 485-493. doi: 10.1017/S10416 10209008916

Nijsten, J. M. H., Leontjevas, R., Pat-El, R., Smalbrugge, M., Koopmans, R. T. C. M., and Gerritsen, D. L. (2017). Apathy: Risk Factor for Mortality in Nursing Home Patients. J. Am. Geriatr. Soc 65 (10), 2182-2189. doi: 10.1111/jgs.15007

Nolan, M., Grant, G., and Nolan, J. (1995). Busy doing nothing: activity and interaction levels amongst differing populations of elderly patients. J. $A d v$. Nurs. 22, 528-538. doi: 10.1046/j.1365-2648.1995.22030528.x

Nørgaard, A., Jensen-Dahm, C., Gasse, C., Hansen, H. V., and Waldemar, G. (2016). Time trends in antipsychotic drug use in patients with dementia: a nationwide study. J. Alzheimers Dis. 49 (1), 211-220. doi: 10.3233/JAD-150481

Ohayon, M. M., Carskadon, M. A., Guilleminault, C., and Vitiello, M. V. (2004). Meta-analysis of quantitative sleep parameters from childhood to old age in healthy individuals: developing normative sleep values across the human lifespan. Sleep 27 (7), 1255-1273. doi: 10.1093/sleep/27.7.1255

Olazarán, J., Reisberg, B., Clare, L., Cruz, I., Peña-Casanova, J., Del Ser, T., et al. (2010). Nonpharmacological therapies in Alzheimer's disease: a systematic review of efficacy. Dement. Geriatr. Cogn. Disord. 30 (2), 161-178. doi: 10.1159/ 000316119

Orgeta, V., Qazi, A., Spector, A. E., and Orrell, M. (2014). Psychological treatments for depression and anxiety in dementia and mild cognitive impairment. Cochrane Database Syst. Rev. 2014 (1), CD009125. doi: 10.1002/14651858. CD009125.pub2

Orgeta, V., Qazi, A., Spector, A., and Orrell, M. (2015). Psychological treatments for depression and anxiety in dementia and mild cognitive impairment: systematic review and meta-analysis. Br. J. Psychiatry 207 (4), 293-298. doi: 10.1192/bjp.bp.114.148130

Osoegawa, C., Gomes, J. S., Grigolon, R. B., Brietzke, E., Gadelha, A., Lacerda, A. L. T., et al. (2018). Non-invasive brain stimulation for negative symptoms in schizophrenia: An updated systematic review and meta-analysis. Schizophr. Res. 197, 34-44. doi: 10.1016/j.schres.2018.01.010

Peters, M. E., Rosenberg, P. B., Steinberg, M., Tschanz, J. T., Norton, M. C., WelshBohmer, K. A., et al. (2012). Prevalence of neuropsychiatric symptoms in CIND and its subtypes: the Cache County Study. Am. J. Geriatr. Psychiatry 20 (5), 416-424. doi: 10.1097/JGP.0b013e318211057d

Petersen, S., Houston, S., Qin, H., Tague, C., and Studley, J. (2017). The Utilization of Robotic Pets in Dementia Care. J. Alzheimers Dis. 55 (2), 569-574. doi: 10.3233/JAD-160703

Porsteinsson, A. P., and Antonsdottir, I. M. (2017). An update on the advancements in the treatment of agitation in Alzheimer's disease. Expert. Opin. Pharmacother. 18 (6), 611-620. doi: 10.1080/14656566.2017.1307340

Porsteinsson, A. P., Drye, L. T., Pollock, B. G., Devanand, D. P., Frangakis, C., Ismail, Z., et al. (2014). Effect of citalopram on agitation in Alzheimer disease: 
the CitAD randomized clinical trial. JAMA 311 (7), 682-691. doi: 10.1001/ jama.2014.93

Porter, C. N., Miller, M. C., Lane, M., Cornman, C., Sarsour, K., and KahleWrobleski, K. (2016). The influence of caregivers and behavioral and psychological symptoms on nursing home placement of persons with Alzheimer's disease: A matched case-control study. SAGE Open Med. 4, 2050312116661877. doi: 10.1177/2050312116661877

Ralph, S. J., and Espinet, A. J. (2018). Increased All-Cause Mortality by Antipsychotic Drugs: Updated Review and Meta-Analysis in Dementia and General Mental Health Care. J. Alzheimers Dis. Rep. 2 (1), 1-26. doi: 10.3233/ ADR-170042

Rattinger, G. B., Schwartz, S., Mullins, C. D., Corcoran, C., Zuckerman, I. H., Sanders, C., et al. (2015). Dementia severity and the longitudinal costs of informal care in the Cache County population. Alzheimers Dement. 11 (8), 946-954. doi: 10.1016/j.jalz.2014.11.004

Rattinger, G. B., Sanders, C. L., Vernon, E., Schwartz, S., Behrens, S., Lyketsos, C. G., et al. (2019). Neuropsychiatric symptoms in patients with dementia and the longitudinal costs of informal care in the Cache County population. Alzheimers Dement. (N. Y.) 5, 81-88. doi: 10.1016/j.trci.2019.01.002

Remington, R., Bechtel, C., Larsen, D., Samar, A., Doshanjh, L., Fishman, P., et al. (2015). A Phase II Randomized Clinical Trial of a Nutritional Formulation for Cognition and Mood in Alzheimer's Disease. J. Alzheimers Dis. 45 (2), 395405. doi: 10.3233/JAD- 142499

Reus, V. I., Fochtmann, L. J., Eyler, A. E., Hilty, D. M., Horvitz-Lennon, M., Jibson, M. D., et al. (2016). The American Psychiatric Association Practice Guideline on the Use of Antipsychotics to Treat Agitation or Psychosis in Patients With Dementia. Am. J. Psychiatry 173 (5), 543-546. doi: 10.1176/appi.ajp.2015.173501

Rios, S., Perlman, C. M., Costa, A., Heckman, G., Hirdes, J. P., and Mitchell, L. (2017). Antipsychotics and dementia in Canada: a retrospective cross-sectional study of four health sectors. BMC Geriatr. 17 (1), 244. doi: 10.1186/s12877017-0636-8

Rocha, F. L., Hara, C., Ramos, M. G., Kascher, G. G., Santos, M. A., de Oliveira Lança, G., et al. (2006). An exploratory open-label trial of ziprasidone for the treatment of behavioral and psychological symptoms of dementia. Dement. Geriatr. Cogn. Disord. 22 (5-6), 445-448. doi: 10.1159/000095804

Roth, H. L. (2012). Dementia and sleep. Neurol. Clin. 30 (4), 1213-1248. doi: 10.1016/j.ncl.2012.08.013

Rozum, W. J., Cooley, B., Vernon, E., Matyi, J., and Tschanz, J. T. (2019). Neuropsychiatric Symptoms in Severe Dementia: Associations with Specific Cognitive Domains The Cache County Dementia Progression Study. Int. J. Geriatr. Psychiatry. 34 (7), 1087-1094. doi: 10.1002/gps.5112

Ruthirakuhan, M. T., Herrmann, N., Abraham, E. H., Chan, S., and Lanctôt, K. L. (2018). Pharmacological interventions for apathy in Alzheimer's disease. Cochrane Database Syst. Rev. 5, CD012197. doi: 10.1002/14651858. CD012197.pub2

Ryu, S. H., Katona, C., Rive, B., and Livingston, G. (2005). Persistence of and changes in neuropsychiatric symptoms in Alzheimer disease over 6 months: the LASER-AD study. Am. J. Geriatr. Psychiatry 13 (11), 976-983. doi: 10.1176/appi.ajgp.13.11.976

Santangelo, G., Trojano, L., Barone, P., Errico, D., Grossi, D., and Vitale, C. (2013). Apathy in Parkinson's disease: diagnosis, neuropsychological correlates, pathophysiology and treatment. Behav. Neurol. 27 (4), 501-513. doi: 10.3233/BEN-129025

Schneider, L. S., Dagerman, K. S., and Insel, P. (2005). Risk of death with atypical antipsychotic drug treatment for dementia: meta-analysis of randomized placebo-controlled trials. JAMA 294 (15), 1934-1943. doi: 10.1001/ jama.294.15.1934

Schneider, L. S., Dagerman, K., and Insel, P. S. (2006a). Efficacy and adverse effects of atypical antipsychotics for dementia: meta-analysis of randomized, placebocontrolled trials. Am. J. Geriatr. Psychiatry 14, 191-210. doi: 10.1097/ 01.JGP.0000200589.01396.6d

Schneider, L. S., Tariot, P. N., Dagerman, K. S., Davis, S. M., Hsiao, J. K., Ismail, M. S., et al. (2006b). Effectiveness of atypical antipsychotic drugs in patients with Alzheimer's disease. New Engl. J. Med. 355, 1525-1538. doi: 10.1056/ NEJMoa061240

Seitz, D. P., Adunuri, N., Gill, S. S., Gruneir, A., Herrmann, N., and Rochon, P. (2011). Antidepressants for agitation and psychosis in dementia. Cochrane Database Syst. Rev. 2, CD008191. doi: 10.1002/14651858.CD008191.pub2
Seitz, D. P., Gill, S. S., Herrmann, N., Brisbin, S., Rapoport, M. J., Rines, J., et al. (2013). Pharmacological treatments for neuropsychiatric symptoms of dementia in long-term care: a systematic review. Int. Psychogeriatr. 25 (2), 185-203. doi: 10.1017/S1041610212001627

Sellers, J., Darby, R. R., Farooque, A., and Claassen, D. O. (2019). Pimavanserin for Psychosis in Parkinson's Disease-Related Disorders: A Retrospective Chart Review. Drugs Aging. 36 (7), 647-653. doi: 10.1007/s40266-019-00655-y

Sepehry, A. A., Sarai, M., and Hsiung, G. R. (2017). Pharmacological Therapy for Apathy in Alzheimer's Disease: A Systematic Review and Meta-Analysis. Can. J. Neurol. Sci. 44 (3), 267-275. doi: 10.1017/cjn.2016.426

Sherman, C., Liu, C. S., Herrmann, N., and Lanctôt, K. L. (2018). Prevalence, neurobiology, and treatments for apathy in prodromal dementia. Int. Psychogeriatr. 30 (2), 177-184. doi: 10.1017/S1041610217000527

Shi, L., Chen, S. J., Ma, M. Y., Bao, Y. P., Han, Y., Wang, Y. M., et al. (2018). Sleep disturbances increase the risk of dementia: A systematic review and metaanalysis. Sleep Med. Rev. 40, 4-16. doi: 10.1016/j.smrv.2017.06.010

Siafarikas, N., Selbaek, G., Fladby, T., Saltyte Benth, J., Auning, E., and Aarsland, D. (2018). Frequency and subgroups of neuropsychiatric symptoms in mild cognitive impairment and different stages of dementia in Alzheimer's disease. Int. Psychogeriatr. 30 (1), 103-113. doi: 10.1017/\$1041610217001879

Soril, L. J., Leggett, L. E., Lorenzetti, D. L., Silvius, J. L., Robertson, D., Mansell, L,, et al. (2014). Effective Use of the Built Environment to Manage Behavioural and Psychological Symptoms of Dementia: A Systematic Review. PLoS One 9 (12), e115425. doi: 10.1371/journal.pone.0115425

Steinberg, M., and Lyketsos, C. G. (2012). Atypical antipsychotic use in patients with dementia: managing safety concerns. Am. J. Psychiatry 169 (9), 900-906. doi: 10.1176/appi.ajp.2012.12030342

Stocks, S. J., Kontopantelis, E., Webb, R. T., Avery, A. J., Burns, A., and Ashcroft, D. M. (2017). Antipsychotic Prescribing to Patients Diagnosed with Dementia Without a Diagnosis of Psychosis in the Context of National Guidance and Drug Safety Warnings: Longitudinal Study in UK General Practice. Drug Saf. 40 (8), 679-692. doi: 10.1007/s40264-017-0538-x

Streim, J. E., Porsteinsson, A. P., Breder, C. D., Swanink, R., Marcus, R., McQuade, R., et al. (2008). A randomized, double-blind, placebo-controlled study of aripiprazole for the treatment of psychosis in nursing home patients with Alzheimer disease. Am. J. Geriatr. Psychiatry 16 (7), 537-550. doi: 10.1097/ JGP.0b013e318165db77

Sugawara Kikuchi, Y., and Shimizu, T. (2019). Aripiprazole for the treatment of psychotic symptoms in patients with dementia with Lewy bodies: a case series. Neuropsychiatr. Dis. Treat. 15, 543-547. doi: 10.2147/NDT.S189050

Sultzer, D. L., Davis, S. M., Tariot, P. N., Dagerman, K. S., Lebowitz, B. D., Lyketsos, C. G., et al. (2008). Clinical symptom responses to atypical antipsychotic medications in Alzheimer's disease: phase 1 outcomes from the CATIE-AD effectiveness trial. Am. J. Psychiatry 165 (7), 844-854. doi: 10.1176/appi.ajp.2008.07111779

Taragano, F. E., Allegri, R. F., Krupitzki, H., Sarasola, D. R., Serrano, C. M., Loñ, L., et al. (2009). Mild behavioral impairment and risk of dementia: a prospective cohort study of 358 patients. J. Clin. Psychiatry 70 (4), 584-592. doi: 10.4088/ JCP.08m04181

Taragano, F. E., Allegri, R. F., Heisecke, S. L., Martelli, M. I., Feldman, M. L., Sánchez, V., et al. (2018). Risk of Conversion to Dementia in a Mild Behavioral Impairment Group Compared to a Psychiatric Group and to a Mild Cognitive Impairment Group. J. Alzheimers Dis. 62 (1), 227-238. doi: 10.3233/JAD170632

Terum, T. M., Andersen, J. R., Rongve, A., Aarsland, D., Svendsboe, E. J., and Testad, I. (2017). The relationship of specific items on the Neuropsychiatric Inventory to caregiver burden in dementia: a systematic review. Int. J. Geriatr. Psychiatry 32 (7), 703-717. doi: 10.1002/gps.4704

Theleritis, C., Siarkos, K., Politis, A. A., Katirtzoglou, E., and Politis, A. (2018). A systematic review of non-pharmacological treatments for apathy in dementia. Int. J. Geriatr. Psychiatry 33 (2), e177-e192. doi: 10.1002/gps.4783

Tractenberg, R. E., Weiner, M. F., Patterson, M. B., Teri, L., and Thal, L. J. (2003). Comorbidity of psychopathological domains in community-dwelling persons with Alzheimer's disease. J. Geriatr. Psychiatry Neurol. 16 (2), 94-99. doi: $10.1177 / 0891988703016002006$

Tractenberg, R. E., Singer, C. M., and Kaye, J. A. (2005). Symptoms of sleep disturbance in persons with Alzheimer's disease and normal elderly. J. Sleep Res. 14 (2), 177-185. doi: 10.1111/j.1365-2869.2005.00445.x 
Trzepacz, P. T., Cummings, J., Konechnik, T., Forrester, T. D., Chang, C., Dennehy, E. B., et al. (2013). Mibampator (LY451395) randomized clinical trial for agitation/aggression in Alzheimer's disease. Int. Psychogeriatr. 25 (5), 707-719. doi: 10.1017/S1041610212002141

Vacas, S. M., Stella, F., Loureiro, J. C., do Couto, F. S., Oliveira-Maia, A. J., and Forlenza, O. V. (2018). Noninvasive brain stimulation for behavioural and psychological symptoms of dementia: A systematic review and meta-analysis. Int. J. Geriatr. Psychiatry 34 (9), 1336-1345. doi: 10.1002/gps.5003

van der Linde, R. M., Stephan, B. C., Savva, G. M., Dening, T., and Brayne, C. (2012). Systematic reviews on behavioural and psychological symptoms in the older or demented population. Alzheimers Res. Ther. 4 (4), 28. doi: 10.1186/ alzrt131

van der Linde, R. M., Dening, T., Stephan, B. C., Prina, A. M., Evans, E., and Brayne, C. (2016). Longitudinal course of behavioural and psychological symptoms of dementia: systematic review. Br. J. Psychiatry 209 (5), 366-377. doi: 10.1192/bjp.bp.114.148403

van der Spek, K., Gerritsen, D. L., Smalbrugge, M., Nelissen-Vrancken, M. H., Wetzels, R. B., Smeets, C. H., et al. (2016). Only $10 \%$ of the psychotropic drug use for neuropsychiatric symptoms in patients with dementia is fully appropriate. The PROPER I-study. Int. Psychogeriatr. 28 (10), 1589-1595. doi: $10.1017 /$ S104161021600082X

Van Leeuwen, E., Petrovic, M., van Driel, M. L., De Sutter, A. I., Vander Stichele, R., Declercq, T., et al. (2018). Withdrawal versus continuation of long-term antipsychotic drug use for behavioural and psychological symptoms in older people with dementia. Cochrane Database Syst. Rev. 3, CD007726. doi: 10.1002/ 14651858.CD007726.pub3

Vandepitte, S., Putman, K., Van Den Noortgate, N., Verhaeghe, S., Mormont, E., Van Wilder, L., et al. (2018). Factors Associated with the Caregivers' Desire to Institutionalize Persons with Dementia: A Cross-Sectional Study. Dement. Geriatr. Cogn. Disord. 46 (5-6), 298-309. doi: 10.1159/000494023

Wang, L. Y., Shofer, J. B., Rohde, K., Hart, K. L., Hoff, D. J., McFall, Y. H., et al. (2009). Prazosin for the treatment of behavioral symptoms in patients with Alzheimer disease with agitation and aggression. Am. J. Geriatr. Psychiatry 17 (9), 744-751. doi: 10.1097/JGP.0b013e3181ab8c61

Wang, G., Albayrak, A., and van der Cammen, T. J. M. (2018). A systematic review of non-pharmacological interventions for BPSD in nursing home residents with dementia: from a perspective of ergonomics. Int. Psychogeriatr. 18, 1-13. doi: $10.1017 /$ S1041610218001679

Wang, Y. C., Tai, P. A., Poly, T. N., Islam, M. M., Yang, H. C., Wu, C. C., et al. (2018). Increased Risk of Dementia in Patients with Antidepressants: A MetaAnalysis of Observational Studies. Behav. Neurol. 2018, 5315098. doi: 10.1155/ 2018/5315098

Watt, J. A., Goodarzi, Z., Veroniki, A. A., Nincic, V., Khan, P. A., Ghassemi, M., et al. (2019). Comparative Efficacy of Interventions for Aggressive and Agitated
Behaviors in Dementia: A Systematic Review and Network Meta-analysis. Ann. Intern. Med. 171, 633-642. doi: 10.7326/M19-0993

Watts, A. S., Mortby, M. E., and Burns, J. M. (2018). Depressive symptoms as a barrier to engagement in physical activity in older adults with and without Alzheimer's disease. PLoS One 13 (12), e0208581. doi: 10.1371/ journal.pone.0208581

Wei, Y., Zhu, J., Pan, S., Su, H., Li, H., and Wang, J. (2017). Meta-analysis of the Efficacy and Safety of Repetitive Transcranial Magnetic Stimulation (rTMS) in the Treatment of Depression. Shanghai Arch. Psychiatry 29 (6), 328-342. doi: 10.11919/j.issn.1002-0829.217106

Weintraub, D., Drye, L. T., Porsteinsson, A. P., Rosenberg, P. B., Pollock, B. G., Devanand, D. P., et al. (2015). Time to Response to Citalopram Treatment for Agitation in Alzheimer Disease. Am. J. Geriatr. Psychiatry 23 (11), 1127-1133. doi: 10.1016/j.jagp.2015.05.006

Wübker, A., Zwakhalen, S. M., Challis, D., Suhonen, R., Karlsson, S., Zabalegui, A., et al. (2015). Costs of care for people with dementia just before and after nursing home placement: primary data from eight European countries. Eur. J. Health Econ. 16 (7), 689-707. doi: 10.1007/s10198-014-0620-6

Yunusa, I., Alsumali, A., Garba, A. E., Regestein, Q. R., and Eguale, T. (2019). Assessment of Reported Comparative Effectiveness and Safety of Atypical Antipsychotics in the Treatment of Behavioral and Psychological Symptoms of Dementia: A Network Meta-analysis. JAMA Netw. Open 2 (3), e190828. doi: 10.1001/jamanetworkopen.2019.0828

Yury, C. A., and Fisher, J. E. (2007). Meta-analysis of the effectiveness of atypical antipsychotics for the treatment of behavioural problems in persons with dementia. Psychother. Psychosom. 76, 213-218. doi: 10.1159/000101499

Zhao, Q. F., Tan, L., Wang, H. F., Jiang, T., Tan, M. S., Tan, L., et al. (2016). The prevalence of neuropsychiatric symptoms in Alzheimer's disease: Systematic review and meta-analysis. J. Affect. Disord. 190, 264-271. doi: 10.1016/ j.jad.2016.04.054

Zwijsen, S., Van der Ploeg, E., and Hertogh, C. (2016). Understanding the world of dementia. How do people with dementia experience the world? International. Psychogeriatrics 28 (7), 1067-1077. doi: 10.1017/S1041610216000351

Conflict of Interest: The authors declare that the research was conducted in the absence of any commercial or financial relationships that could be construed as a potential conflict of interest.

Copyright (C) 2020 Magierski, Sobow, Schwertner and Religa. This is an open-access article distributed under the terms of the Creative Commons Attribution License (CC BY). The use, distribution or reproduction in other forums is permitted, provided the original author(s) and the copyright owner(s) are credited and that the original publication in this journal is cited, in accordance with accepted academic practice. No use, distribution or reproduction is permitted which does not comply with these terms. 